\title{
Psychological Characteristics and Mental Health Education Strategies for Post-00s College Students
}

\author{
Xiaoyan Ding \\ School of Mechanical and Electronic Engineering \\ Wuhan University of Technology \\ Wuhan, China
}

\begin{abstract}
The post-00s college students have become the majority of freshmen in colleges and universities. They have their own prominent psychological characteristics in thinking and value pursuit. Being more confident and optimistic, they have much stronger self-consciousness while lack of social communication skills. However, they are also faced with fiercer social competition in present time featured with fast-growing economy and upgrading network information, which express higher requirements of their psychological quality. In accordance with the psychological characteristics of post-00s college students, overall planning in the whole society should be made to realize effective connection of mental health education in all stages. As the principle role in cultivating and transporting high-quality talents for the development of the country, colleges and universities should focus on making concerted efforts to open up multiple educational channels and upgrade mental health education for post-00s students.
\end{abstract}

Keywords-post-00s college students; psychological characteristics; mental health; education

\section{INTRODUCTION}

With the post-00s college students becoming the main group in colleges and universities, college students' mental health education has entered a new period. Post-00s college students have been living in the social environment featured with fast development of national economy, increasingly pluralistic culture and rapidly developed network information. Moreover, the booming New Media Era and big data technology result in college students' distinct psychological characteristics of the time, which has caused various psychological problems concerning academic career planning, life adaptation and social interaction. Therefore, colleges and universities should adjust their mental health education strategies according to the psychological characteristics of post-00s college students, which is an important issue to be tackled urgently in the current social and college mental health education.

\section{PSYCHOLOGICAL CHARACTERISTICS OF POST-00S COLLEGE STUDENTS}

\section{A. More Personalized Pursuit of Value With Obvious Tendency of Pragmatism and Utilitarianism}

Born and raised in the new century of China with rapid economic development, the post-00s generation has enjoyed relatively better material conditions since their childhood. During their growth, they pay less attention to material needs and pay more attention to personal emotional experience and value realization[3]. Therefore, compared with post- 80s and psot-90s, the post-00s generation has more diversified value orientation and no longer put personal value pursuit and goals in a fixed target. They are more likely to pursue personalized value and plan their own development path based on historical background, social needs, their own capabilities and characteristics [2]. At the same time, they are more inclined to make value judgment and evaluation based on individuals with less collectivism and more emphasis on pragmatism and utilitarianism. They go after practical benefits. These are the most prominent characteristics of post-00s college students.

Therefore, many post-00s college students lack crisis awareness of present life and the future. They prefer a more comfortable state, which breeds all kinds of problems in understanding and planning for the future. They are not only lack of initiative in all kinds of educational activities organized by the colleges and universities, but also lack of planning for their four-year college career and setting goals for their future target including employment, education and development. Most of them will not realize that they are directly facing the cruelty of employment and other practical problems until graduation, which caused great psychological pressure. Meanwhile, the frustration caused by inaccurate selfrecognition and positioning, unclear self-planning and other factors will lead to many more psychological problems.

\section{B. More Flexible Thinking and Weak Discriminability}

Compared with those born in the 1980s and 1990s, the post-00s generation grew up in the period of rapid national economic development. Overall cultural levels of their families and emphasis on education have been significantly improved. And also, they were born and grew up in the Internet Era. For them, the Internet is their life, and digital survival is their way of life since childhood so that they are called "the Internet Natives". They use, contact and understand network media in the process of growing up. They are able to obtain fresh information and knowledge more quickly and conveniently, which makes the post-00s generation have a broader vision and more flexible thinking.

However, in this information globalization time of rapid upgraded information, the post-00s, innocent and lacking of social experience, are inadequate in recognition and discriminability when faced with numerous and complicated influx of huge amounts of information. They are also equipped 
with insufficient understanding of the complexity of the surroundings and prone to extreme emotions, which can lead to ideological confusion and perplexity, causing the actual inappropriate behavior of all kinds.

\section{Confident and Optimistic, Lack of Psychological Endurance and Anti-pressure Ability}

Born in the 2000s, they grew up in the new century and new era with abundant material resources. Since childhood, they have received family care and more investment in education from multiple generations [6]. Therefore, they have a stronger sense of self-superiority and are more confident and optimistic about their ability. They are also full of enthusiasm and hope for life, and have more positive expectations for the future. The post-00s generation is faced with competition for high-quality educational resources in all stages of their growth. Due to great learning pressure, they are more likely to feel nervous and anxious.

At the same time, with the reform and opening up entering a crucial stage, Chinese society has also entered a transition period. The social environment is more complex with more diversified values, which makes post-00s college students unable to establish stable beliefs. Due to the favorable living environment and excessive care from parents, post-00s college students have more prominent demands for personal spirit, psychology and emotion. It is difficult to maintain the time and state outside their comfort zone. Their psychological bearing ability and anti-pressure ability are obviously insufficient. Based on this, post-00s college students face more intense social competition. Once frustrated, they would be faced with all kinds of psychological problems.

\section{Stronger Self-consciousness and Lack of Social Communication Skills}

Influenced by social environment and family education, post-00s college students are more self-centered and have a strong sense of subjectivity, emphasizing individuality and uniqueness. They are more likely to challenge authority to prove themselves, and more likely to pursue respect and selfdemand, which are the common characteristics of the post-00s college students. However, they have less team spirit in learning and competition. They prefer to be alone rather than being in a group. They are more likely to stick to their own position and emphasize more on safeguarding their own rights and interests.

Due to the rapid development of network information technology, most of them are more inclined to communicate in a virtual network platform to communicate with people. There are many more phubbers among post-00s college students wandering in the virtual digital world and concealing themselves in real communication. They prefer to restrain their mood and lack of contact with the real world as well as their own real feelings. Many post-00s students have no interest in all kinds of collective activities organized by classes, colleges and schools after they enter the university so that their social communication skills cannot be improved. They lack communication skills and practical ability in interpersonal communication, and they know little about empathy. Therefore, post-00s college students are prone to encounter setbacks in real social communication. With poor psychological endurance and anti-pressure ability, they would be much easier to come across depression, irritability and anxiety, which then evolve into psychological problems[5].

\section{StRategIES OF MENTAL HEALth EdUCATION FOR POST-00S COLLEGE STUDENTS}

As the new youth in the new era and the state-trained socialist builders and successors, post-00s college students have presented new challenges to the mental health education in colleges and universities due to their collective psychological characteristics and psychological problems. College mental health education for post-00s college students needs to be optimized from three aspects: overall social planning, joint efforts of college education and innovative educational forms and contents.

\section{A. Overall Planning to Realize Effective Connection of Mental Health Education in All Stages}

The psychological characteristics of post-00s college students have a very obvious brand of The Times, which is deeply influenced by each stage from their birth to their entrance into the university. Their psychological development tasks and psychological problems in primary and secondary schools need adequate attention and help, not only started from universities. Under the current domestic educational environment, most students have not received systematic mental health education before entering the university, nor have little knowledge of mental health. Therefore, it is necessary to carry out overall planning at the social level, strengthen the popularization of mental health knowledge, and realize the effective connection of mental health education from primary and secondary schools to universities.

Mental health education in both primary and secondary schools and universities require comprehensive overall planning, focusing on different emphasis on each stage of the psychological development of teenagers. And also, more attention should be paid to the continuity of students' mental and personality development so as to lay the psychological foundation for the development of post-00s college students. This can enable those students with mental problems and even psychological barriers to get effective prevention and treatment, effectively preventing college students' psychological crisis.

\section{B. Joint Efforts of Colleges and Universities to Open Up Multiple Educational Channels}

Psychological problems of post-00s college students in school are caused by such multiple factors as course study, establishment of values, interpersonal relationship, campus activities, and economic conditions and so on. Thus, it is necessary for colleges and universities to give full play to educators of various relating aspect including the specialized course teachers, ideological and political educators, counselors as well as professional teachers of mental health education. Linkage educational mechanism of multiple channels should be set up covering major functional departments including office of academic affairs, student management department, 
logistics department and department of mental health education so as to jointly create an effective educational atmosphere of aspiration, unity and mutual assistance.

The role of the specialized course teachers should be given full play to help post-00s College students build a good sense of professional identity, establish a scientific and reasonable academic career plan, formulate professional learning strategies and lay a solid foundation for professional learning so as to successfully complete their academic tasks. The ideological and political educators can make efforts to guide the post-00s College students in their ideological growth with the scientific theory [4]. This attributes a great deal in solving their weakness in ideas and values in real life and leads them to combine personal development with social progress and national prosperity, to have a rational view of individual and collective interest. The students should dialectically pursue their personal value in the context of national demand and social need so as to achieve the organic integration of the Individuals and the country. The student management apartment should make efforts to care for the growth of post-00s college students, establish a scientific and reasonable crisis prevention and control pre-warning system, and constantly improve the management methods and means of post-00s college students in practice to help them grow up.

It is necessary to reinforce the team construction of counsel ors to meet the demand of tackling practical problems. Students' ideological dynamics, psychological state and daily life should be given full concern on the basis of harmonious relationship between teachers and students. The logistics support department should do a good job to ensure a favorable growing environment in living and studying for college students. Mental health education departments in colleges and universities should further strengthen their professional construction, spread mental health knowledge in all aspects to improve psychological counseling and crisis intervention.

\section{Innovation on the Form and Content of Mental Health Education}

Since the post-00s college students have strong learning autonomy, traditional form of tough indoctrination is difficult to meet their cognitive and psychological needs. Based on the psychological characteristics of post-00s college students, they need psychological health education with a stronger sense of participation, more diverse forms and richer contents. This requires thinking and innovation in the form and content of mental health education in colleges and universities.

When it comes to form of the mental health education for post-00s College students, educators can make effective use of network space including social media, network media and We Media where college students are gathering, on the basis of adherence to correct value guidance and public opinion direction. The network can be fully developed as the carrier of mental health education courses. For example, various educational forms can be exploited such as interactive WeChat official account, MOOC, We Media platforms represented by Tik Tok and webcast to create familiarity and closeness with the students. The publicity function of the media can be favorably applied to convey methods and measures of improving the quality of psychological education[1]. Psychological knowledge can be effectively penetrated to each individual student through those diverse channels to enable the students actively learn psychological knowledge. Multiple Practical means presided over by professional psychological teachers can be applied in forms of psychological group counseling, psychological salon, psychological counseling studio and so on, which are vivid and interesting so that students can be more actively involved with more participation and sense of gain. Mental health education activity mode should be innovated, such as the psychological theme class meeting, psychological knowledge competition, psychological drama and other high-quality activities to strengthen the effective interaction between students. The psychological knowledge should be integrated into well-formed and lively psychological theme activities to stimulate students' interest in psychology.

As for the content of mental health education for post-00s college students, educators must be good at grasping the popular vane and integrate proper popular elements into the process of education. More attractive and stimulating education content should be designed in accordance with the psychological characteristics and concentrated psychological problems of post-00s college students. It is of great significance to stimulate the students' interest and concerns of mental health education. For example, in view of the adjustment problems and emotional problems easily exploded among freshmen in September every year, a targeted psychological survey and mental health education for freshmen is of much necessity.

To tackle the unhealthy phenomenon such as the "younger age trend of college students", severe dependency and weak interpersonal ability among the post-00s college students, targeted mental health group activities should be designed to strengthen their social communication ability and psychological quality.

\section{CONCLUSION}

The new era has endowed the post-00s college students with new roles and historical missions, and also brought new challenges to college mental health educators. The mental health education of post-00s college students needs to attract the wide attention of the society so as to strengthen the popularization of mental health knowledge, and focus on the characteristics of their mental development in every stage. At the same time, colleges and universities have the sense of responsibility to cultivate and transport high-quality professionals for the development of the country, and they need to fully form a joint effort in psychological education, break through the multi-channel path of psychological education, innovate the form and content of psychological health education for post-00s college students, so as to implement the fundamental task of strengthening moral education and cultivating people. 


\section{REFERENCES}

[1] Cai Yamin. Discussion on Innovation Path of College Students' Mental Health Education [J]. The Party Building and Ideological Education in Schools, 2016,(2) (In Chinese)

[2] Ma Chuan. An empirical study on the mental health level of post-00s college students [J]. Ideological \& Theoretical Education, 2019, (3). (In Chinese)

[3] Wang Haijian. Group characteristics and ideological and political education strategies of post-00s college students [J]. Ideological \& Theoretical Education, 2018,(10)(In Chinese)
[4] Zhao Huili. Research on ideological and political education mode of post-00s college students [J]. The Party Building and Ideological Education in Schools, 2016(11). (In Chinese)

[5] Zhou Tu, The psychological status and countermeasures of college students born after 1995 and 2000 under the new situation [J]. Data of Culture and Education, 2018,(6) (In Chinese)

[6] Zhu Zhiping. On the psychological characteristics and management strategies of post-00s college students [J]. Course Education Research, 2019(21). (In Chinese) 